\title{
As redes sociais como ferramentas de comunicação mercadológica para segmentos de públicos regionais: um caso de produtos de bens de consumo
}

SOCIAL NETWORKS AS TOOLS FOR MARKETING COMMUNICATION FOR REGIONAL PUBLIC SEGMENTS: A CASE OF CONSUMER GOODS PRODUCTS

\llcorner

\section{Monica Franchi Carniello}

Doutora em Comunicação e Semiótica (PUC), Professora do Programa de Mestrado em Gestão e Desenvolvimento Regional da Universidade de Taubaté. monicafcarniello@gmail.com.

\section{Gustavo Ribeiro Rosa}

Mestre em Gestão e Desenvolvimento Regional pela Universidade de Taubaté. gustavo. rosa7@hotmail.com.

Recebido em 10 de abril de 2014. Aprovado em 18 de agosto de 2014

\section{Resumo}

As redes sociais digitais são, atualmente, um importante meio de comunicação que pode ser utilizado pelas empresas como ferramenta para divulgar produtos e serviços. Apesar do alcance global da mídia Internet, essas redes permitem uma interação mais próxima com segmentos específicos de públicos, possibilitando um canal de comunicação direto com grupos que se formam a partir de interesses comuns. Estimular a formação de grupos em torno de produtos, serviços ou marcas é uma estratégia de comunicação mercadológica. Este artigo teve como objetivo analisar as estratégias e resultados de uma campanha nas redes sociais digitais de uma linha de produtos de bens de consumo. Com base na coleta de dados e por meio do método de estudo de caso, de pesquisa bibliográfica e pesquisa documental, de abordagem qualitativa e de caráter exploratório, analisando-se os resultados obtidos, foi possível verificar na ação publicitária, a campanha "Ultra-light" e que ocorrereu aumento no volume das vendas de uma determinada linha de produtos de bens de consumo, devido à forte divulgação nas redes sociais digitais e voltando aos patamares normais de volume de vendas após o encerramento da campanha. Sendo possível sua aplicação para um determinado público regional, como foi a utilização da campanha no município de São Paulo e dirigida a um cliente específico de rede de farmácias.

Palavras-chave: Marketing Digital. Propaganda regional. Redes sociais digitais. 


\section{Abstract}

Social networks are currently an important means of communication that can be used by companies to advertise products and services. Despite the global reach of the Internet media, these networks allow closer interaction with specific segments of the public, allowing a direct channel of communication with groups that are formed from common interests. Encouraging the formation of groups around products, services or brands is a marketing communication strategy. This article aimed to analise the strategies and results of a social media campaign of consumer goods products. Based on data collection using method of case study, literature review and desk research, with qualitative approach and exploratory level, analyzing the results, we found for the case study in the campaign "Ultra-light" that there was an increase in the volume of sales of a particular consumer goods products line, due to the strong disclosure in digital social networks and that it returned to normal levels of sales volume after the end of the campaign. Being possible its application to a particular regional public, as was the use of the campaign in the city of São Paulo, and directioning to a specific customer of network pharmacies.

Keywords: Digital Marketing. Regional advertising. Digital social networks.

\section{Introdução}

Com a reestruturação do sistema midiático a partir do advento da comunicação digital, as empresas mudaram sua maneira de realizar negócios. As empresas que deram conta desta mudança perceberam que os consumidores estão cada vez mais exigentes e passaram a trabalhar suas estratégias de Marketing de forma bastante diferente após o advento da Internet 2.0. Devido a Internet permitir um ambiente de colaboração rápido e acessível a qualquer momento, as empresas que buscaram atuação no ambiente da web precisaram se adaptar ao novo comportamento dos consumidores imersos na cultura digital.

Este artigo centraliza sua discussão sobre a utilização das redes sociais digitais como meio de divulgação de produtos, demonstrando como essas redes se tornam canais representativos de comunicação com os públicos consumidores de diversos produtos. A compra de produtos do caso analisado, por enquanto, não é feita nas redes sociais digitais, no entanto, o trabalho analisa os reflexos nas vendas por causa da sua divulgação nesse meio, e o efeito da propaganda ou promoção realizada que incentiva a curto ou longo prazo a compra de produtos.

Foi possível verificar o fenômeno das redes sociais digitais, em termos de conceito nas ciências sociais, que segundo Marteleto (2001, p. 72) representam “[...] um conjunto de participantes autônomos, unindo ideias e recursos em torno de valores e interesses compartilhados".

\footnotetext{
$62 \frac{\text { Comunicação \& Inovação, PPGCOM/USCS }}{\text { v. 15, n. } 29 \text { (61-80) jul-dez } 2014}$
} 
São nestas ideias, valores e interesses compartilhados que estão as oportunidades de negócio, sendo necessário que a área de Marketing trabalhe cada vez mais em estratégias de divulgação que atendam aos desejos destes consumidores que buscam por atenção, produtos e serviços que atendam suas necessidades, como declara Levine et al. (2000, p. 69):

A web nos dá uma oportunidade de escapar dos limites impostos pela mídia às demasiadas noções de divulgação. Os nascentes esforços de divulgação na Web têm sua gênese em uma ardente necessidade de dizer algo, mas seu sucesso final decorre das pessoas dispostas a ouvir, precisando mutuamente de escutar as próprias vozes e de responder à altura.

As pessoas às quais Levine (2000) se refere são aquelas que representam suas empresas. O perfil do novo consumidor é de alguém que deseja ser ouvido por aquele que representa a própria empresa. Neste sentido, as redes sociais digitais possuem esta característica, que permite estreitar os relacionamentos e dar respostas mais rápidas e eficazes aos grupos de clientes, aproximando o diálogo entre uma empresa e seu público.

Este artigo teve como objetivo analisar as estratégias e resultados de uma campanha nas redes sociais digitais de uma linha de produtos de bens de consumo.

\section{Referencial Teórico}

\section{Marketing Digital}

Com a evolução da Internet, a disseminação do e-commerce (Comércio eletrônico) e a vasta utilização das redes sociais, desbravar novos caminhos para atingir os consumidores tornou-se tarefa cada vez mais árdua para a área de Marketing.

Segundo definição de Limeira (2007, p. 3):

Marketing é uma palavra em inglês derivada de market, que significa mercado. É utilizada para expressar a ação voltada para o mercado. Assim entende-se que uma empresa ou uma pessoa pratica o marketing quando tem o mercado como razão e o foco de suas ações.

Para Limeira (2007, p. 4), “o marketing passou a ser entendido como a função empresarial que cria valor para o cliente e gera vantagem competitiva duradoura para a empresa por meio da gestão estratégica do composto de marketing".

Limeira (idem) ainda explica que "composto de marketing é o conjunto de quatro ferramentas que a empresa utiliza na criação de valor para o cliente, a saber: produto, preço, promoção e ponto de distribuição.

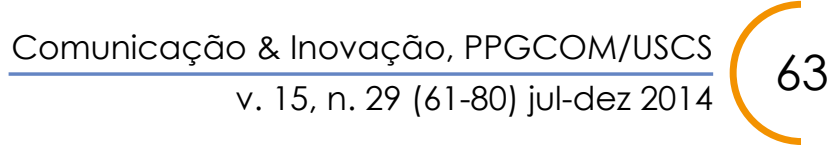


Na promoção estão as ações voltadas para estratégias de comunicação aos clientes (propaganda, eventos, publicidade) e também de promoções de vendas (brindes, sorteios, descontos), neste segmento pode-se considerar o uso das redes sociais digitais para fomentar sugestões, críticas e elogios para os produtos que estão sendo divulgados, estabelecer ambientes de diálogo e cooperação, estreitar relacionamentos e prover informação e entretenimento.

Os hábitos de consumo evoluíram, a tecnologia também permitiu novas formas de atuação, surge o marketing segmentado, no qual as empresas focam suas ações em determinados grupos de consumidores, de acordo com seu perfil e exigências. $\mathrm{Na}$ década de 1990 surge o marketing individualizado, no qual o cliente é tratado individualmente, com relacionamento próximo e de forma interativa, com uma maior abrangência de produtos e serviços voltados as suas necessidades.

Finalmente, devido à evolução da tecnologia de informação e da comunicação (TIC) e à ascensão da Internet, o marketing individualizado evoluiu para o marketing digital, que estabelece um conjunto de ações de marketing por meio de canais eletrônicos, por exemplo, a própria Internet (LIMEIRA, 2007).

Com o conceito de Internet 2.0, outros canais de comunicação como blogs, wikis, redes sociais digitais, vídeos, podcasts, entre outros meios, também passaram a ser utilizados com maior frequência pelos profissionais de marketing.

Para Telles (2009) o marketing precisa de agilidade em suas campanhas para fidelizar os usuários:

Seria inocente acreditar que a geração digital permaneça fiel a uma marca por muito tempo, certamente não com as opções, as proliferações dos substitutos e a paridade competitiva que existe hoje. Esqueça conceitos antigos de como gerar fidelidade a um produto ou serviço, tenha em mente que agora temos de gerar preferência imediata e isto exige agilidade no marketing (p. 28).

Os profissionais de marketing têm o desafio de entender os hábitos de consumo dos consumidores e estabelecer estratégias para conquistá-los. Sobre consumo Canclini (1996, p. 60) propõe a definição: "o consumo é o conjunto de processos socioculturais em que se realizam a apropriação e o uso dos produtos".

As inovações tecnológicas interferem no processo de consumo, como Canclini descreve:

Quando vemos a proliferação de objetos e de marcas, de redes de comunicação e de acesso ao consumo da perspectiva dos movimentos de consumidores e de suas demandas, percebemos

$64 \frac{\text { Comunicação \& Inovação, PPGCOM/USCS }}{\text { v. 15, n. } 29 \text { (61-80) jul-dez } 2014}$ 
que as regras - móveis - da distinção entre os grupos, da expansão educacional e das inovações tecnológicas e da moda também intervêm nestes processos (1996, p.61).

O consumo é útil para a expansão dos mercados e da reprodução da força de trabalho (CANCLINI, 1996), compreender os impulsos e desejos dos consumidores é uma poderosa arma para a empresa tornar-se mais competitiva num mercado de tantas ofertas.

Os profissionais de marketing reconhecem o potencial das mídias sociais, conforme Coutinho (2007, p.32) que enumera os motivos pelos quais as redes sociais virtuais deveriam interessar aos profissionais de marketing:

- $\mathrm{O}$ envolvimento dos internautas com as redes sociais virtuais é crescente;

- As redes sociais virtuais geram impacto sobre a percepção de modernidade da marca;

- As redes sociais virtuais têm capacidade de gerar novas idéias para a comunicação mercadológica;

- As redes sociais virtuais conseguem reunir rapidamente tanto os "advogados da marca" como os consumidores que tiveram experiências negativas, grupos particularmente ativos na divulgação de opiniões;

- As redes sociais virtuais atuam como uma rede de "early warning", indicando possíveis problemas antes mesmo que eles se articulem como queixas/percepções.

\section{Redes Sociais Digitais}

As comunidades virtuais “[...] têm surgido para atender às necessidades de comunicação, informação e entretenimento, dos clientes" (ALBERTIN, 2010, p. 31).

Para Cipriani (2011, p. 5), as comunidades virtuais são:

pequenas tribos formadas dentro de uma rede social, onde pessoas se conectam para conversar sobre os assuntos de seu interesse e descobrir que, no final das contas, todos temos várias características em comum quando temos objetivos parecidos.

No entanto, Castells (2003, p. 107) aponta que a "grande transformação da sociabilidade em sociedades complexas ocorreu com a substituição de comunidades espaciais por redes como formas fundamentais de sociabilidade".

Castells também observa que, "em toda a sociedade, "construir redes" emergiu como uma nova forma de organização das atividades humanas, e ele cunhou o termo "sociedade em rede" para descrever e analisar essa nova estrutura social" (CASTELLS, 2003 apud DUARTE, QUANDT, SOUZA, 2008, p. 18).

$$
\frac{\text { Comunicação \& Inovação, PPGCOM/USCS }}{\text { v. 15, n. } 29 \text { (61-80) jul-dez } 2014} 65
$$


Atualmente as redes sociais digitais são exemplo destas "comunidades virtuais" e "sociedade em rede", tendo enorme expansão no mundo e no público de todas as idades.

A partir do ano 2000, após o estouro da bolha da internet, em vez de páginas com conteúdos estáticos, diversas empresas passaram a oferecer produtos e serviços on-line, nesta nova geração de comunidades e serviços, popularmente conhecida como Web 2.0, surgiram as mídias sociais, como explica Cipriani (2011, p. 5):

São ferramentas que permitem a formação de discussões entre as pessoas e empresas na rede. Elas promovem vida em comunidade e cooperação, possibilidade de alterar ou misturar criações de terceiros, melhor experiência on-line, diversão, educação, controle e domínio do que queremos buscar ou usar, abrindo espaço para assuntos muitos específicos e colocando o usuário em primeiro lugar e no centro das atenções. A Web 2.0 é a plataforma tecnológica que sustenta as mídias sociais viabilizando blogs, wikis, sites de compartilhamento de foto e vídeo, compartilhamento de listas de favoritos e redes sociais.

Dentre as mídias sociais mais divulgadas estão as redes sociais, cuja principal característica, segundo Cipriani $(2011$, p. 6), “[...] é a possibilidade de conectar-se a várias pessoas simultaneamente por meio de listas de amigos, seguidores e desconhecidos".

Para Recuero (2004, p. 7), as redes sociais virtuais são: "Esses sistemas funcionam com o primado fundamental da interação social, ou seja, buscando conectar pessoas e proporcionar sua comunicação e, portanto, podem ser utilizados para forjar laços sociais".

Telles (2009) comenta que na Web 2.0 a colaboração se torna tão importante quanto os meios existentes de geração de conteúdo.

A interatividade dá às empresas a oportunidade de desenvolver produtos, vender e fixar marcas. A Web 2.0 representa a transição para um novo paradigma, onde a colaboração ganha força suficiente para concorrer com os meios tradicionais de geração de conteúdo (TELLES, 2009, p. 43).

São várias as redes sociais digitais em operação: Orkut, Twitter, Facebook, Flickr, Spaces.Live, Blogger, Linkedin, Reclame Aqui, Tumblr, Youtube, entre outras. Inicialmente destinadas aos jovens interessados em trocas de informações e em ampliar amizades, depois passou a ter o poder de influenciar as pessoas, divulgar marcas e promover produtos.

Como declara Recuero (2009, p. 30), "em termos gerais, as conexões em uma rede social são constituídas dos laços sociais que, por sua vez, são formados através da interação social entre os atores".

$66 \frac{\text { Comunicação \& Inovação, PPGCOM/USCS }}{\text { v. 15, n. } 29 \text { (61-80) jul-dez } 2014}$ 
Recuero (2009) explica que, segundo a obra de Primo (2003), existem duas formas de interação dentro do contexto de interação mediada por computador: a interação mútua e a interação reativa.

Recuero (2009, p. 32) conclui que: "Estas formas distinguem-se pelo "relacionamento mantido" (Primo, 2003, p. 61) entre os agentes envolvidos". Desta forma:

[...] interação mútua é aquela caracterizada por relações interdependentes e processos de negociação, em que cada interagente participa da construção inventiva e cooperada da relação, afetando-se mutuamente; já a interação reativa é limitada por relações determinísticas de estímulos e resposta (PRIMO, 2003, p. 62 apud RECUERO, 2009, p. 32).

Recuero (2009, p. 33) esclarece que:

É claro que a interação reativa, por suas próprias limitações, acaba reduzindo o espectro de relações sociais que possa gerar e, consequentemente, de laços sociais. A interação mútua, por outro lado, como permite a inventividade, como explica Primo, pode gerar relações mais complexas do ponto de vista social.

Pode-se tomar o Facebook como exemplo de uma interação mútua, porque tem impacto nas relações sociais, gerando ações de ambos os agentes envolvidos, seja com o botão de "curtir" ou nos comentários feitos em suas publicações. No caso da reação reativa, pode-se considerar um acesso de uma página na Internet, através de um hiperlink, devido a algum estímulo, o usuário dirige-se a uma nova página clicando no link.

A interação mútua nas redes sociais digitais pode demonstrar o tipo de relação que os atores possuem, podendo estar vinculada aos laços sociais existentes.

Recuero (2009, p. 38) define laços sociais como:

O laço é a efetiva conexão entre os atores que estão envolvidos nas interações. Ele é resultado, deste modo, da sedimentação das relações estabelecidas entre agentes. Laços são formas mais institucionalizadas de conexão entre atores, constituídos no tempo e através da interação social.

Recuero (idem) explica que "[...] as redes sociais analisadas na Internet podem ser de dois tipos: as redes emergentes e as redes de filiação ou redes de associação".

As redes sociais do tipo emergentes, segundo sua definição:

$$
\frac{\text { Comunicação \& Inovação, PPGCOM/USCS }}{\text { v. 15, n. } 29 \text { (61-80) jul-dez } 2014} 67
$$


[...] são aquelas expressas a partir das interações entre os atores sociais. São redes cujas conexões entre os nós emergem através das trocas sociais realizadas pela interação social e pela conversação através da mediação do computador (RECUERO, 2009, p. 94).

Para Recuero (ibid., p. 95) “[...] é uma rede emergente porque ela é constantemente construída e reconstruída através das trocas sociais".

Ainda declara que:

[...] essas redes são mantidas pelo interesse dos atores em fazer amigos e dividir suporte social, confiança e reciprocidade. Esse capital é o principal investimento desses atores, embora posteriormente, outros tipos de capital possam também surgir (2009, p. 95).

Pode-se exemplificar como redes emergentes, os sites de blogs ou weblogs que contém uma lista de comentários mantidos entre os atores, a partir de uma publicação de conteúdo e que dificilmente podem ser apagados.

As redes sociais do tipo filiação ou associativas, segundo explicação de Recuero (2009, p. 97):

[...] são aquelas derivadas das conexões "estáticas" entre os atores, ou seja, das interações reativas (Primo, 2003) que possuem um impacto na rede social. São redes cujas conexões são forjadas através dos mecanismos de associação ou de filiação dos sites de redes sociais. É o caso, por exemplo, das listas de "amigos" no Orkut, da lista de pessoas que alguém segue no Twitter, etc.

Recuero (ibid., p. 100) explica as diferenças entre essas redes:

As diferenças mais significativas, no entanto, aparecem relacionadas à dinâmica dessas redes. Enquanto as redes de filiação são bastante estáveis e mudam mais raramente (e quanto mais difícil for deletar uma conexão, mais a rede ficará estável), tendem a crescer e agregar mais nós; as redes emergentes são bastante mutantes e tendem a apresentar dinâmicas de agregação e ruptura com frequência.

Pode-se exemplificar como redes de filiação ou associativas, o site do Facebook, no qual uma "amizade" pode ser mantida por um longo período de tempo em virtudes dos laços sociais forjados que caracterizam a estabilidade existente nestas redes.

Recuero (ibid., p. 102) define sites de rede sociais como "os espaços utilizados para a expressão das redes sociais na internet”. 
Para o autor (ibid., p. 107), "o que é diferencial nos sites de redes sociais é que eles são capazes de construir e facilitar a emergência de tipos de capital social que não são facilmente acessíveis aos atores sociais no espaço off-line".

Por exemplo, no Facebook um usuário pode ter uma grande quantidade de "amigos", o que nas relações sociais fora da internet não é fácil de acontecer, enquanto nas redes sociais digitais torna-o mais visível e com maior possibilidade de popularidade.

As conexões obtidas nas redes sociais são mantidas pelo sistema e não pelas interações. Os sites de redes sociais amplificam a expressão da rede social e a conectividade dos grupos sociais (RECUERO, 2009).

Recuero (ibid.) detalha em sua obra que no capital social de Bertolini e Bravo (2001), existem valores que são comumente relacionados aos sites de redes sociais, tais como: visibilidade, reputação, popularidade e autoridade.

Quanto à visibilidade, os sites de redes sociais permitem aos usuários estarem mais conectados, aumentando, com isso, sua visibilidade social a partir dessas conexões, permitindo também aumento no suporte social e obtenção de informações, ou seja, quanto mais aumentam as conexões, maiores as chances de um suporte social e de receber informações quando forem solicitadas, além de manter laços sociais com quem está fisicamente distante (RECUERO, 2009).

Com isso, Recuero (ibid.) explica que a visibilidade está conectada ao capital social relacional (BERTOLIN \& BRAVO, 2001).

O conceito de reputação implica diretamente no fato de que há informações sobre quem somos e o que pensamos, auxiliando outros a construir impressões sobre nós. A reputação acaba sendo um julgamento do outro, de suas qualidades. Não importando o número de conexões que possui, mas sim das impressões deixadas, o que o outro pode estar pensando de nós.

Os sites de redes sociais permitem maior controle das impressões que são emitidas e dadas. Neste ponto, as redes sociais na internet são extremamente efetivas para a construção de reputação (RECUERO, 2009).

Recuero (ibid.) explica que, "muitos autores também relacionam a reputação como um mecanismo de seleção dos parceiros em uma rede social (GOLBECK; HENDLER, 2004). Através da reputação é possível escolher em quem confiar e com quem transacionar".

Por conta disto, as empresas preocupam-se muito com aquilo que está sendo "falado" delas nas redes sociais, o efeito viral das redes sociais na internet pode causar grandes prejuízos para a reputação, para a imagem de uma empresa.

Por fim, Recuero (ibid., p. 111) conclui:

$$
\frac{\text { Comunicação \& Inovação, PPGCOM/USCS }}{\text { v. 15, n. } 29(61-80) \text { jul-dez } 2014} 69
$$


A reputação, portanto, está associada ao capital social relacional e cognitivo de acordo com a proposta de Bertolini e Bravo (2001). Relacional porque é uma consequência das conexões estabelecidas pelos autores. Cognitivo porque está também relacionada ao tipo de informação publicada pelo ator social.

Recuero (idem), com base nos conceitos de Bertolini e Bravo (2001), define a popularidade como:

A popularidade é um valor relacionado à audiência, que é também facilitada nas redes sociais na internet. Como a audiência é mais facilmente medida na rede, é possível visualizar as conexões e as referências a um indivíduo, a popularidade é mais facilmente percebida. Trata-se de um valor relativo à posição de um ator dentro de sua rede social. Um nó mais centralizado na rede é mais popular, porque há mais pessoas conectadas a ele e, por conseguinte, esse nó poderá ter uma capacidade de influência mais forte que outros nós na mesma rede. Esses nós poderiam ser também aqueles classificados por Barabási (2003) como conectores.

Por conta disto, algumas empresas utilizam artistas famosos, pessoas conceituadas em suas carreiras, para divulgação de seus produtos e marcas nas redes sociais na internet, porque possuem forte influência sobre os outros, devido a sua popularidade e reputação.

Recuero (2009) explica que a autoridade refere-se ao poder de influência que o ator possui em sua rede social e, associado a isso, a percepção que os demais atores possuem da reputação dele. A autoridade também está voltada ao capital social cognitivo de acordo com os tipos de Bertolini e Bravo (2001).

Recuero (2009, p. 114) conclui “(...) a medida de autoridade é uma medida que só pode ser percebida através dos processos de difusão de informações nas redes sociais e da percepção dos atores dos valores contidos nessas informações”.

\section{Redes Sociais Digitais No Brasil}

No Brasil, os hábitos dos internautas nas mídias sociais podem ser verificados na pesquisa realizada pela comScore (2013), empresa especializada em medições de comércio eletrônico.

Os usuários brasileiros despenderam um tempo médio de 9,3 horas mensais em visitas a sites nas mídias sociais, durante o período de Fevereiro de 2010 à Dezembro de 2012, um crescimento de $167 \%$, conforme Gráfico 1.

$70 \frac{\text { Comunicação \& Inovação, PPGCOM/USCS }}{\text { v. 15, n. } 29 \text { (61-80) jul-dez } 2014}$ 


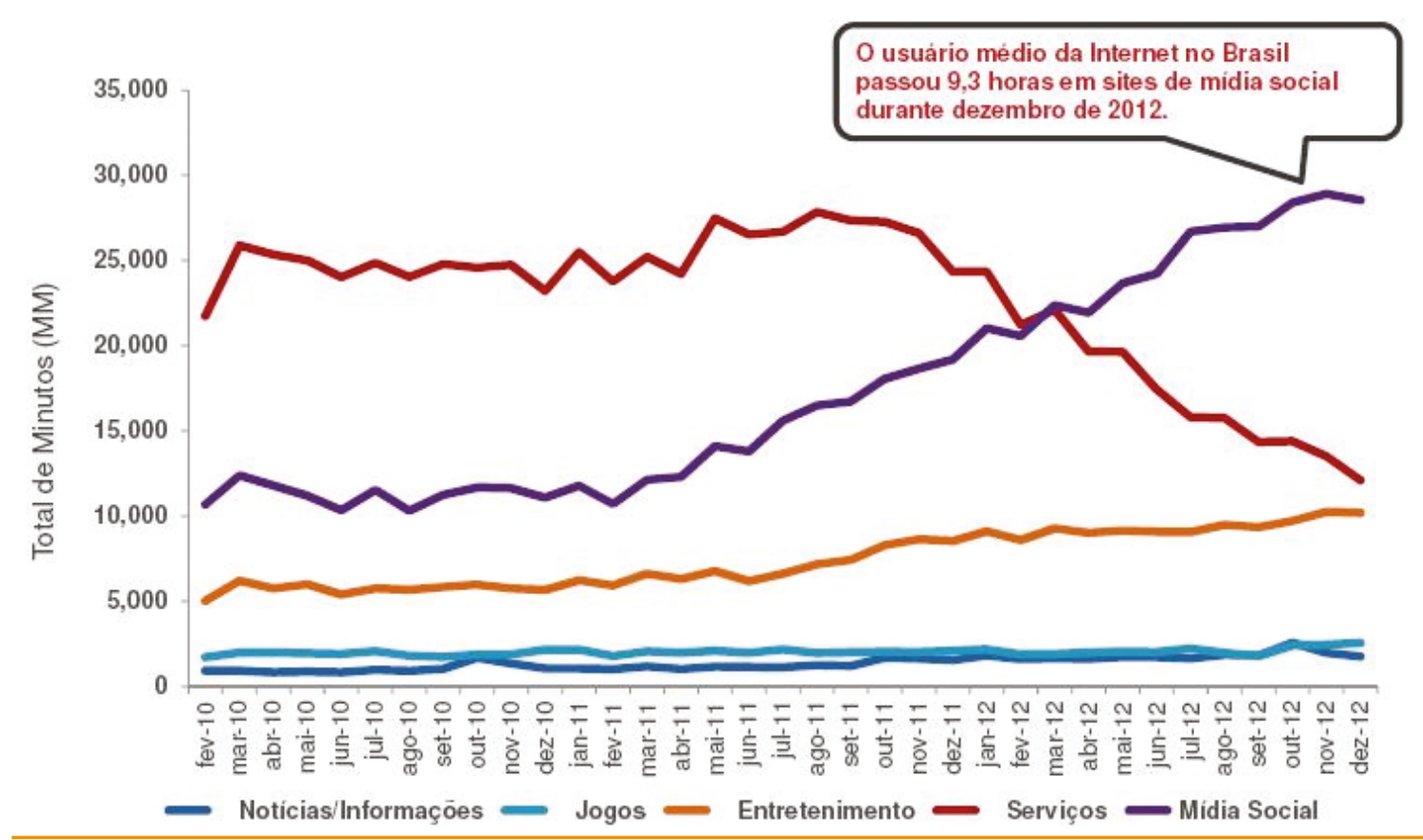

Gráfico 1 - Tempo médio de visitas em sites de mídias sociais no Brasil Fonte: comScore (2013).

Na liderança dos sites de mídias sociais estão as redes sociais digitais Facebook e Orkut, com 43.986 e 12.346 visitantes (únicos) respectivamente, com uma média de idade de 32 anos, conforme o Gráfico 2.

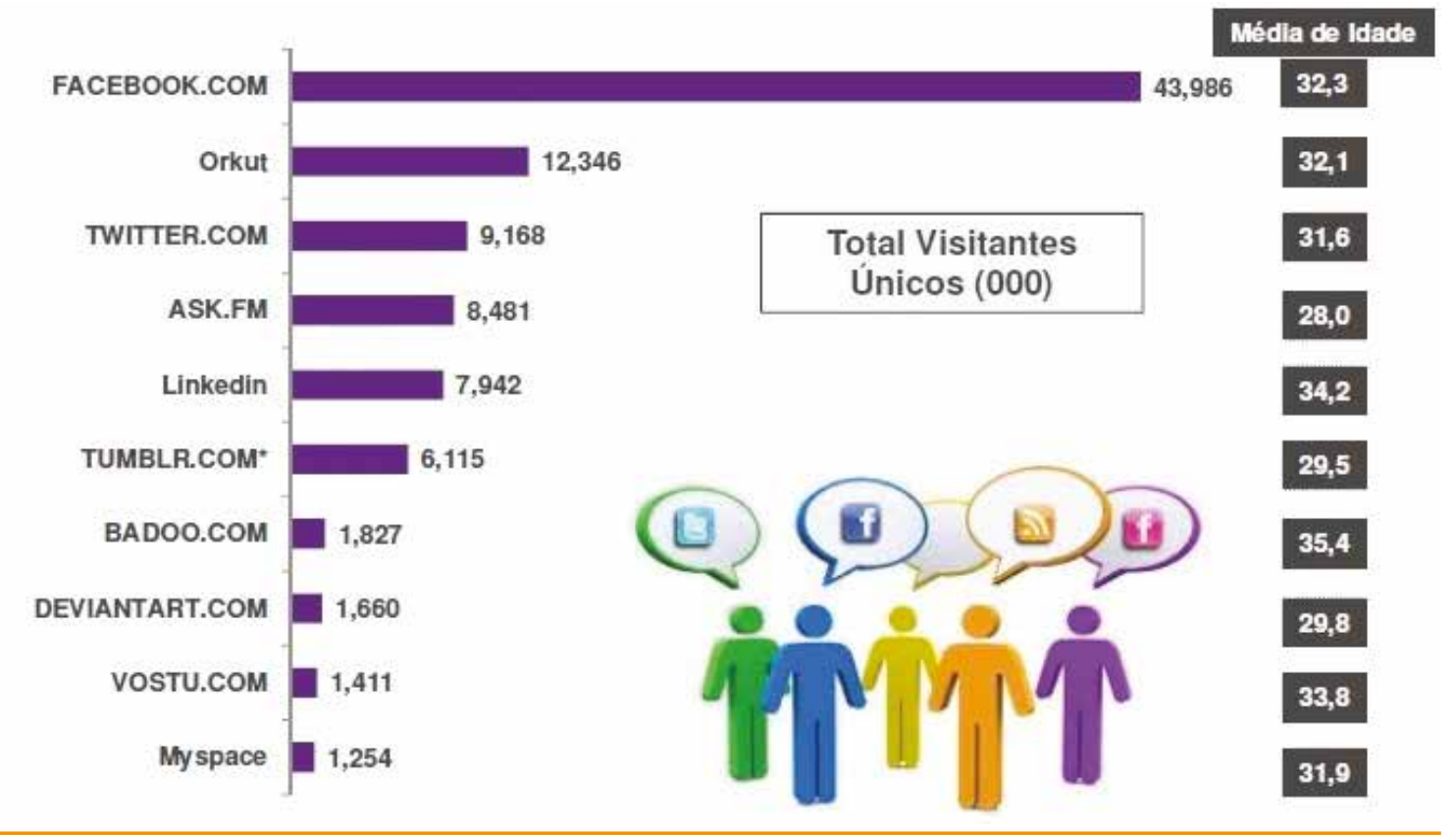

Gráfico 2 - Visitas em sites de mídias sociais no Brasil

Fonte: comScore (2013).

NOTA: Dezembro 2012. 
Outra informação que chama a atenção na pesquisa da comScore é a crescente evolução do tempo gasto nas redes sociais no Brasil em comparação com o Global, uma média de quase 10 horas em Dezembro de 2012, conforme Gráfico 3.

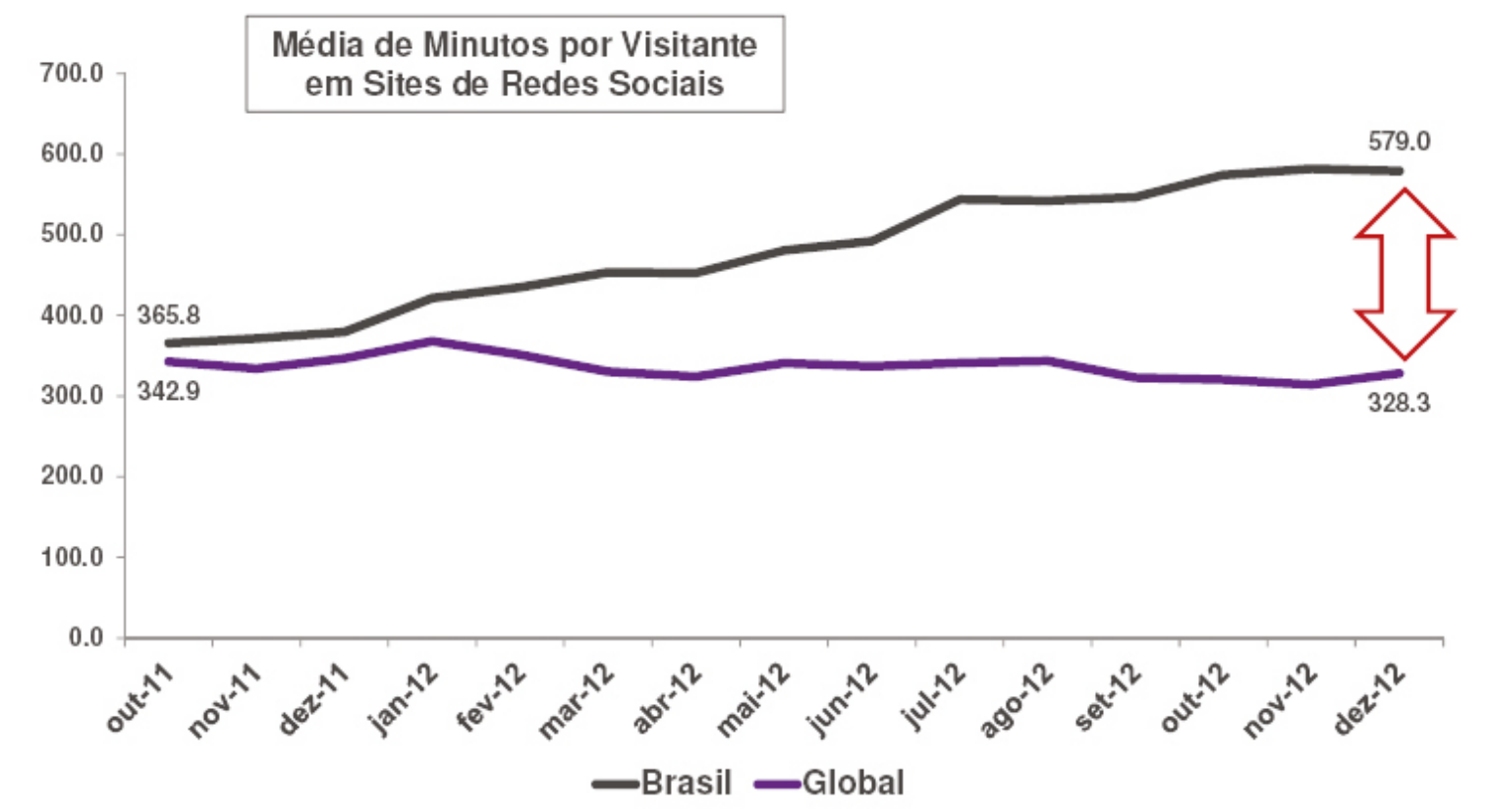

Gráfico 3 - Evolução tempo gasto em sites de redes sociais

Fonte: comScore (2013)

NOTA: acima de 15 anos.

As redes sociais digitais têm emergido ao longo de vários anos para redefinir a maneira do pensamento sobre a disseminação de mensagens de marketing. A habilidade que os consumidores têm para identificar marcas de interesse e conectar-se com elas permite novas formas de interação entre marcas e consumidores (ComSCORE, 2012).

\section{Método}

Por meio de revisão bibliográfica, pesquisa documental e estudo de caso, de abordagem qualitativa e de caráter exploratório, foi analisada a utilização das redes sociais digitais como ferramentas de comunicação mercadológica para segmentos de públicos, por meio do estudo de caso da empresa Johnson \& Johnson do Brasil Ind. e Com. de Produtos para Saúde Ltda., sediada no município de São Paulo, denominada neste trabalho como Johnson \& Johnson.

A pesquisa de estudo de caso analisou a campanha chamada de "Ultra-light", que aconteceu nos meses de junho e julho de 2011, por meio do jogo "Caçada bolhas Ultralight”, que era adquirido gratuitamente na Internet para celulares iPhone. O consumidor

$72 \frac{\text { Comunicação \& Inovação, PPGCOM/USCS }}{\text { v. 15, n. } 29 \text { (61-80) jul-dez } 2014}$ 
era premiado com cupons durante a "caçada de bolhas" em frente às lojas de farmácias da rede Droga Raia no município de São Paulo, estes cupons poderiam ser compartilhados nas redes sociais digitais do Facebook para os amigos. No momento da compra, o cliente apresentava o código do cupom, válido somente na compra de produtos da linha Neutrogena Ultra-light e ganhava um produto de brinde no final da compra.

A campanha utilizou o meio das redes sociais digitais pela facilidade de atingir a segmentos de público local e regional, que neste caso foi o canal de negócio de farmácia, além de contar com um número significante de usuários nas redes sociais que acessam habitualmente a média de 10 horas/mês.

Segundo Yin (2001), as principais razões que justificam um estudo de caso podem ser verificadas conforme demonstra o Quadro 1.

\begin{tabular}{cc}
$\begin{array}{c}\text { Razões para utilizar o estudo de caso } \\
\text { O Fenômeno de interesse que não pode ser estudado } \\
\text { fora de seu ambiente natural. }\end{array}$ & $\begin{array}{c}\text { Justîîcativa para a pesquisa em análise } \\
\text { A utilização do marketing digital é analisada na prática } \\
\text { por meio da rede social digital Facebook. }\end{array}$ \\
\hline O estudo focaliza eventos contemporâneos. & $\begin{array}{c}\text { É uma tendência atual dentro das tecnologias de } \\
\text { informação e da comunicação. }\end{array}$ \\
\hline $\begin{array}{c}\text { O controle dos sujeitos e eventos não é necessário. } \\
\text { Pesquisar uma área na qual poucos estudos prévios } \\
\text { tenham sido realizados. }\end{array}$ & $\begin{array}{c}\text { Neste caso, não existe identificação dos usuários, ocorrerá } \\
\text { uma pós-análise do número de acessos e interações } \\
\text { realizados. }\end{array}$ \\
\hline $\begin{array}{c}\text { Responder a perguntas de tipo como e por quê, } \\
\text { possibilitando a compreensão da complexidade do } \\
\text { processo. }\end{array}$ & $\begin{array}{c}\text { As análises deste estudo pretendem compreender a tona a carencia de estudos } \\
\text { efetividade do uso desta tecnologia na divulgação e } \\
\text { vendas de produtos de bens de consumo. }\end{array}$ \\
\hline
\end{tabular}

Quadro 1 - Razões que justificam um estudo de caso

Fonte: O autor - adaptado de Yin (2001).

Na campanha "Ultra-light", feita para os produtos da linha Neutrogena Ultralight, com base na amostra dos meses de junho e julho de 2011, a coleta foi realizada pela agência de publicidade contratada pelo desenvolvimento da campanha promocional, que entregou para a empresa os seguintes dados, que foram usados como fonte documental dessa pesquisa:

- Número de Pageviews;

- Número de downloads (baixar arquivo) do jogo "Caçada bolhas Ultra-light";

- Número de cupons distribuídos.

Para uma maior abrangência de análise, foi feita uma coleta de dados da base de dados IMS Health (IMS), instituto de pesquisa especializado no canal farmácia, um dos 
institutos líderes na área de serviços e tecnologia para a indústria de bens de consumo e que está presente em mais 100 países no mundo (IMS HEALTH, 2013). Por meio dos dados obtidos da IMS foi possível analisar a evolução das vendas dos produtos da linha Neutrogena Ultra-light na rede de farmácias Droga Raia, onde a campanha foi feita com exclusividade.

Na campanha dos produtos da linha Neutrogena Ultra-light, a análise teve o objetivo de verificar o volume de vendas de produtos que foi incentivado por meio da divulgação nas redes sociais e do jogo "Caçada bolhas Ultra-light", que premiavam os usuários com cupons que davam direito a um produto brinde.

Foi realizada uma análise da evolução das vendas, verificando-se as vendas antes e depois do período da campanha promocional para verificar se houve de fato aumento devido à execução da campanha promocional nas redes sociais digitais do Facebook. Além disso, foram analisados dados de outro cliente concorrente no mesmo período da amostra, o qual não participou desta campanha, para analisar a taxa de evolução de vendas de um cliente e do outro.

\section{Resultados e Discussão}

A concorrência entre as empresas de bens de consumo é muito acirrada no mercado brasileiro, são muitos competidores dentro de um mesmo mercado.

No caso da marca Neutrogena não é diferente, por conta disso a ação publicitária, campanha "Ultra-light", voltada para a linha de produtos Ultra-light, buscou promover o crescimento de suas vendas e da participação da marca no mercado do canal farmacêutico no segmento de produtos de beleza e cuidados da pele. As redes sociais digitais foram estrategicamente utilizadas pela facilidade que tem de atingir a segmentos de público local e regional e ser uma ferramenta de comunicação de massa de baixo custo.

No Gráfico 4 foi analisada a evolução da marca Neutrogena desde 2009 até 2012, verificou-se um constante crescimento da marca diante dos demais concorrentes, ocupando, até o ano de 2012, a $3^{\text {a }}$ posição no ranking de mercado. O mercado neste segmento é bastante concorrido e ter $1 \%$ de aumento de participação já pode ser considerado um bom crescimento para a marca.

O foco da campanha foi promover a divulgação da linha de produtos Ultralight, indicada para os primeiros cuidados com a pele, e o aumento das vendas da marca Neutrogena Ultra-light - os resultados foram muito expressivos.

A campanha, além de ser realizada nas redes sociais digitais, contou com o apoio de tabloides, ações nas lojas (divulgação) e pontos extras na loja.

$74 \frac{\text { Comunicação \& Inovação, PPGCOM/USCS }}{\text { v. 15, n. } 29 \text { (61-80) jul-dez } 2014}$ 


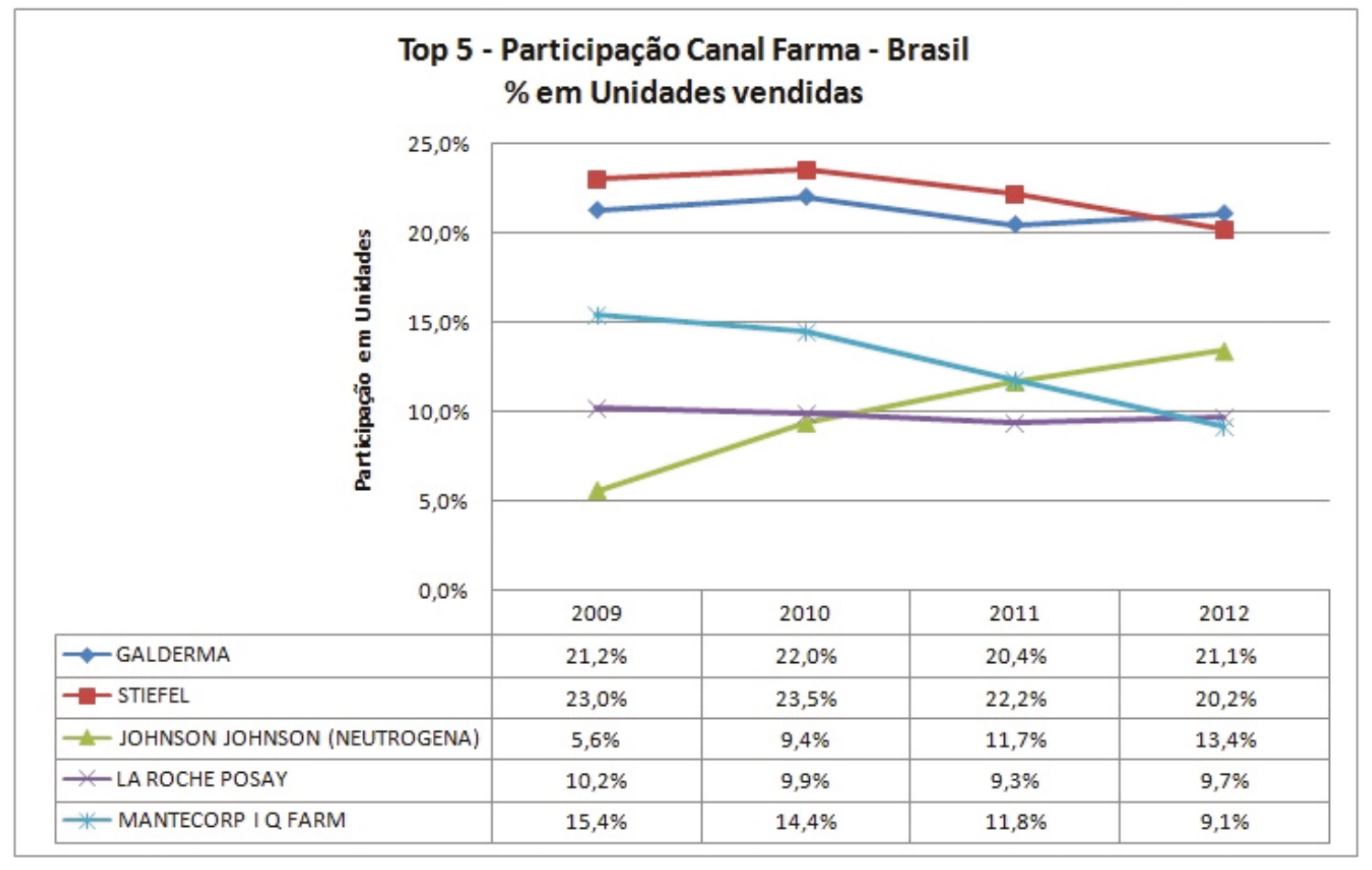

Gráfico 4 - Participação de mercado canal farma Brasil - em \% de unidades vendidas Fonte: Johnson \& Johnson Indústria e Comércio de Produtos para Saúde Ltda. (2011b).

NOTA: Com base nos dados IMS Health.

A mecânica da campanha "Ultra-light" envolveu os seguintes passos:

a. Primeiro foi feita a divulgação da campanha "Ultra-light" na página Neutrogena Brasil no Facebook;

b. O usuário, para participar da campanha, precisava ter um celular iPhone e baixar (download) o jogo "Caçada bolhas Ultra-light" na Apple store (Loja Apple) na internet; por meio do link: http://itunes.apple.com/us/app/id445398321?mt=8 ;

c. O jogo indicava a farmácia Droga Raia mais próxima e apresentava informações dos produtos da linha Ultra-light;

d. Para conseguir os cupons de desconto oferecidos na campanha, bastava "capturar as bolhas" em frente às lojas Droga Raia.

e. A cada bolha capturada o usuário ganhava um cupom na forma de um "código", que dava direito a um produto brinde (Neutrogena Deep Clean), no momento da compra de produtos da linha Neutrogena Ultra-light, conforme Figura 1.

Houve também a divulgação da campanha por meio de um vídeo no Youtube, acessado pelo link: http://www.youtube.com/watch?v=zGx2cgNZvNw . 


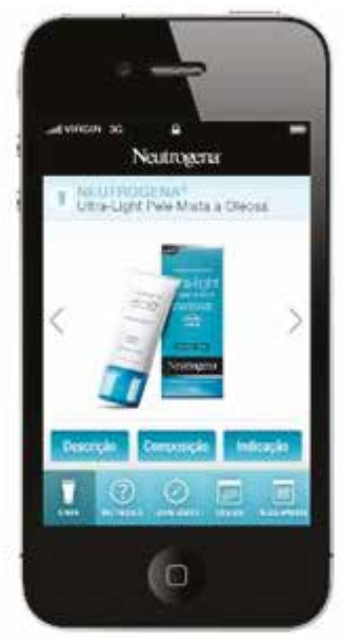

a) Obtenha informações sobre cada produto da linha Ultra-light.

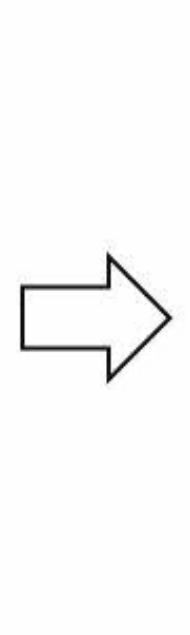
b) Capture as bolhas virtuais em frente às Lojas Droga Raia.

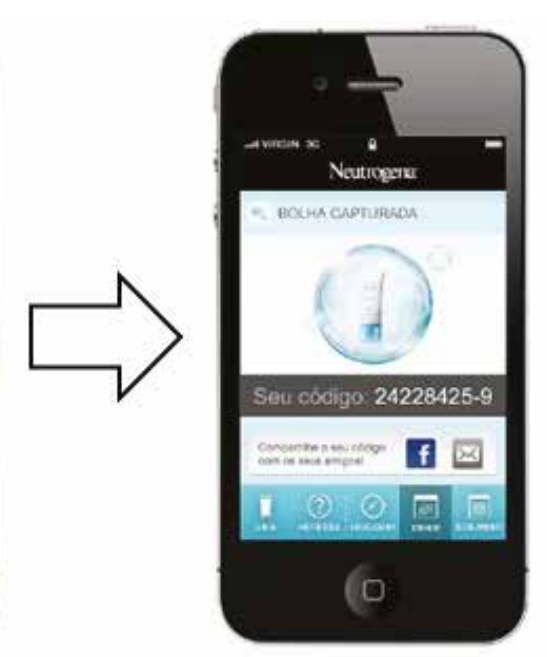

c) Ganhe cupons de desconto e compartilhe com os amigos no Facebook

Figura 1 - Jogo "caçada bolhas Ultra-light"

Fonte: Johnson \& Johnson Indústria e Comércio de Produtos para Saúde Ltda. (2011b).

Os resultados atingidos foram bastante expressivos para uma marca que o público ainda não conhecia apropriadamente.

A campanha Ultra-light registrou uma alta movimentação de acessos na página Neutrogena Brasil, conforme Quadro 2:

\begin{tabular}{cc} 
Item & Número de pageviews \\
Visualizações de páginas & 46,570 \\
\hline Promoção & 33,851 \\
\hline Produtos & 6,843 \\
\hline Tela inicial & 3,679 \\
\hline Regulamento & 2,197 \\
\hline \hline
\end{tabular}

Quadro 2 - Acessos na página Neutrogena Brasil no Facebook

Fonte: Johnson \& Johnson Indústria e Comércio de Produtos para Saúde Ltda. (2011b).

Foram entregues 625 cupons entre o período de junho e julho de 2011, que premiaram os consumidores com um produto brinde.

No Gráfico 5 verifica-se a evolução de vendas dos produtos da linha Ultra-light (em unidades) nas lojas de farmácias da rede Droga Raia no município de São Paulo em 2011.

Verificou-se que no período que ocorreu a campanha, as vendas subiram automaticamente, comparando-se o mês de maio/2011 e junho/2011, e continuaram a subir em julho/2011. Como reflexo do mês de julho/2011, o mês de agosto/2011 continuou em alta, mesmo com o término da campanha. A partir do mês de setembro/2011 


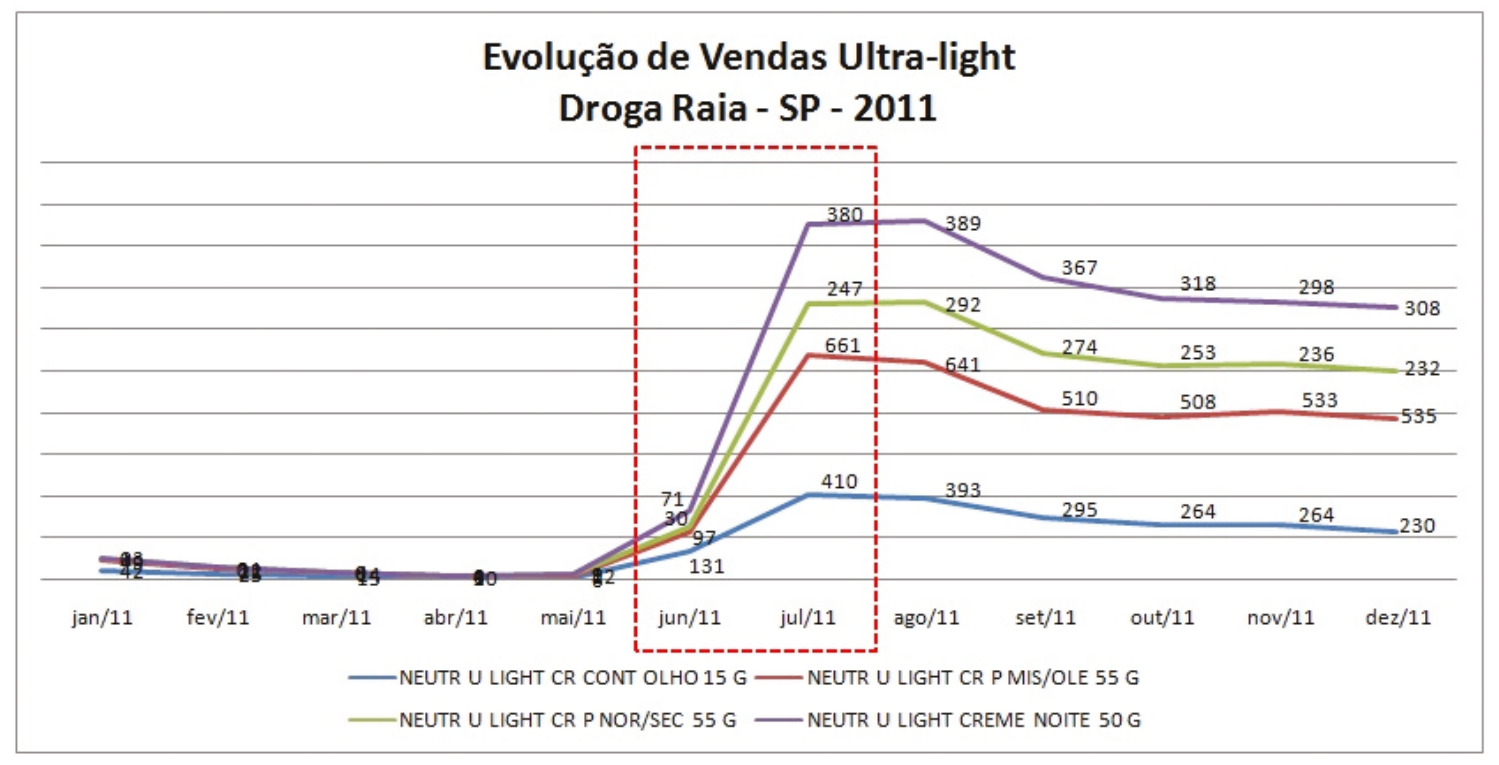

Gráfico 5 - Evolução de vendas Ultra-light em SP - Droga Raia

Fonte: Johnson \& Johnson Indústria e Comércio de Produtos para Saúde Ltda. (2011b).

NOTA: Com base nos dados da IMS Health.

até dezembro/2011 as vendas caíram, mas com bons resultados de vendas segundo a empresa.

Outra análise realizada foi da taxa de incremento de vendas do cliente Droga Raia versus o cliente Drogasil. Pode-se verificar no Gráfico 6 que as vendas da Droga Raia sofreram maior incremento nos meses da campanha, do que as vendas da Drogasil, e a partir do mês de agosto ficaram praticamente equivalentes. Houve um pico de vendas na Drogasil em abril/2011 que não pode ser identificado devido à falta de informações. Acredita-se que deva ter ocorrido alguma atividade de marketing ou vendas que elevou as vendas neste período.

Na página de Neutrogena Brasil no Facebook foram postados alguns agradecimentos pela promoção e sobre a maneira de atendimento na farmácia Droga Raia, conforme Figura 2.

\section{Conclusão}

A partir da evolução da internet 2.0 e das mídias sociais, o perfil de comportamento do consumidor mudou, verificando-se, atualmente, uma participação muito mais ativa, exigindo que suas necessidades sejam atendidas, buscando um diálogo mais próximo com as empresas. Por outro lado, as empresas viram-se na obrigação de participarem desse ambiente digital, com novas práticas de marketing, pois as ações tradicionais já não atingiam o público com tanta eficiência. Desta forma, passou a ser comum a divulgação 


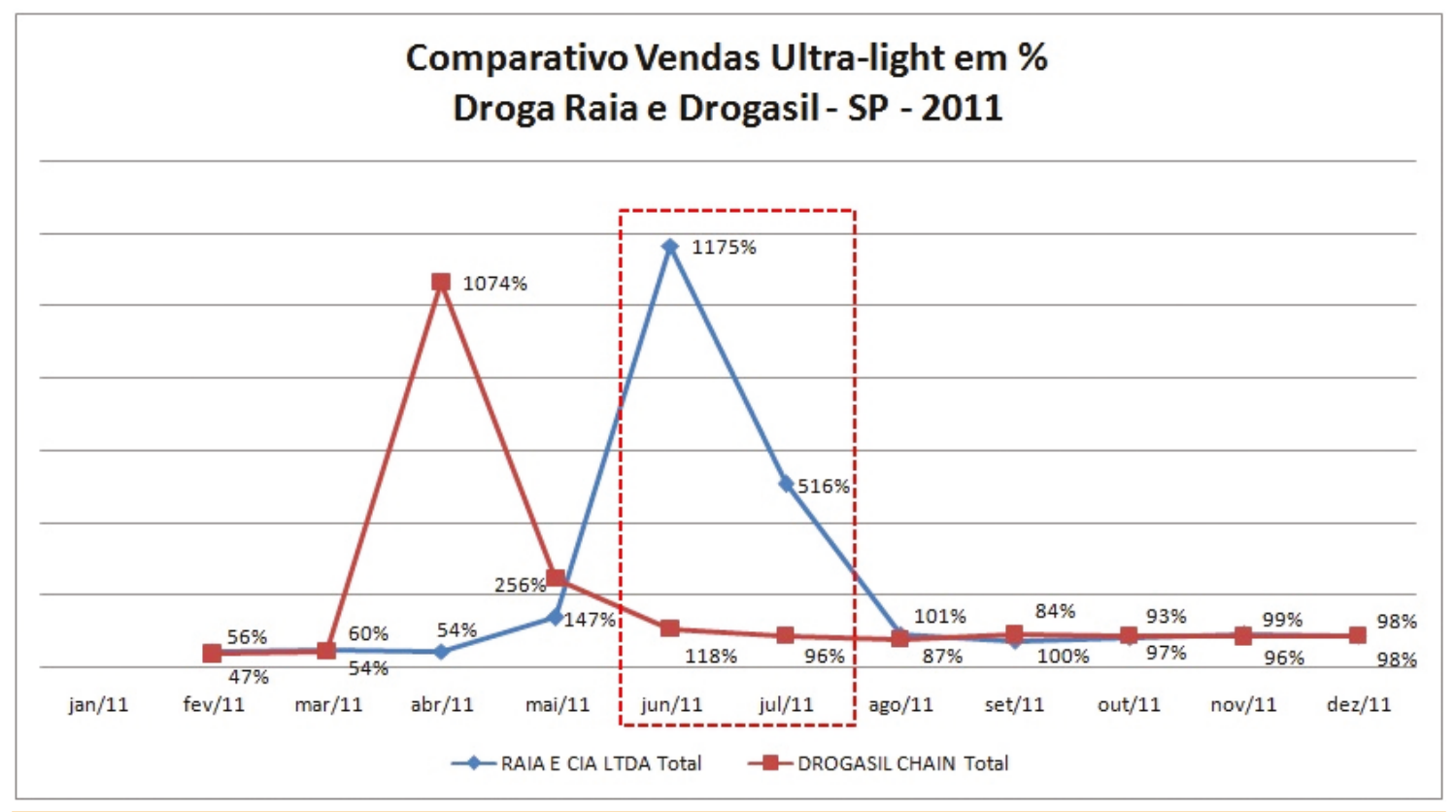

Gráfico 6 - Comparativo de vendas Ultra-light em SP - Droga Raia e Drogasil Fonte: Johnson \& Johnson Indústria e Comércio de Produtos para Saúde Ltda. (2011b). NOTA: Com base nos dados da IMS Health.

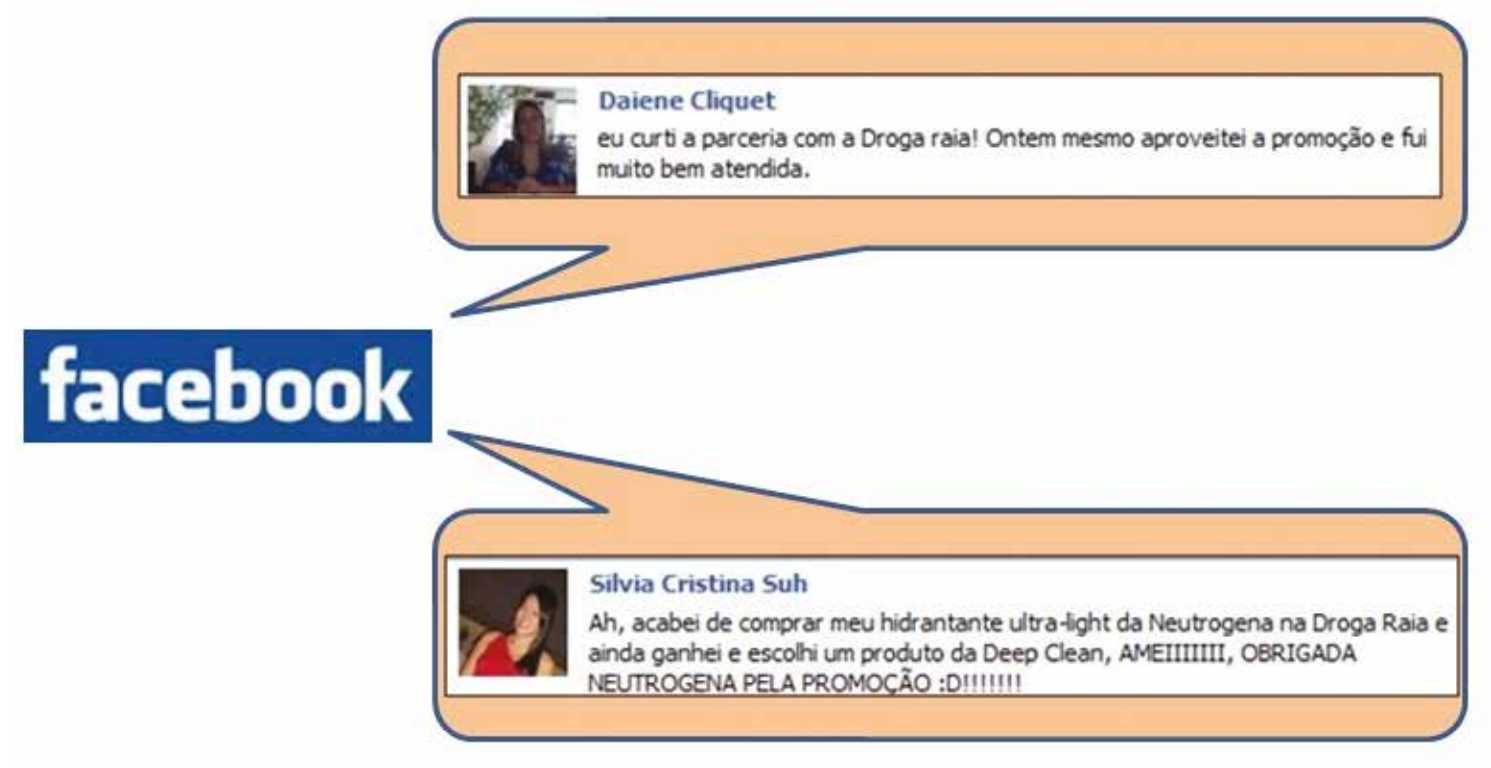

Figura 2 - Comentários na página Neutrogena Brasil

Fonte: Johnson \& Johnson Indústria e Comércio de Produtos para Saúde Ltda. (2011a).

de produtos e realização de campanhas nas redes sociais digitais, visto que as mesmas permitem alcançar os segmentos de público local ou regional, e de uma comunicação de massa de baixo custo.

Por meio da análise da ação publicitária, a campanha "Ultra-light", verificou-se um aumento no volume de vendas devido à utilização das redes sociais nesta campanha 
promocional, ao fazer a análise das vendas antes e depois da campanha nos meses de junho e julho de 2011, verificou-se um crescimento significativo no início da campanha em junho, um crescimento sustentável em julho e mantido até agosto mesmo com o encerramento da mesma, seguido de uma queda crescente até final de dezembro de 2011, evidenciando-se que nos meses em que ocorreu a campanha, os produtos da linha Ultra-light da marca Neutrogena tiveram aumento de vendas devido à forte divulgação nas redes sociais digitais, apoiadas também por ações de tabloides, divulgação e ponto extra nas lojas da rede Droga Raia. Além desta análise, verificou-se no período da campanha o aumento do volume de vendas da Droga Raia, comparando-se suas vendas com a de sua concorrente na época, a Rede Drogasil. Após o encerramento da campanha, a Droga Raia voltou a praticar seu volume de vendas em patamares normais, equivalentes ao da Drogasil.

Como sugestão para novos estudos, seria relevante analisar se o sucesso obtido pela empresa Johnson \& Johnson seria o mesmo para outras empresas com marcas de produtos menos conhecidas no mercado.

Conclui-se que os empresários precisam romper com a desconfiança sobre as redes sociais e acreditar que por meio delas podem ser realizados grandes negócios. Não estar presente neste ambiente digital significa abrir espaço para seus concorrentes e não aproveitar as oportunidades de negócio que esse novo ambiente tem para oferecer.

\section{Referências}

Albertin, A. L., Comércio eletrônico: modelo, aspectos e contribuições de sua aplicação. 6 ed. São Paulo: Atlas, 2010.

Amaral, A.; Recuero, R.; Montardo,S.(Org.). Blogs.com: estudos sobre blogs e comunicação. São Paulo.: Momento Editorial, 2009.

CAnClini, N.G. O consumo serve para pensar. In: Consumidores e cidadãos - conflitos multiculturais da globalização. Rio de Janeiro: UFRJ, 1996, p. 59-73.

Castells, M. A galáxia da Internet. Rio de Janeiro: Zahar, 2003.

CIPRIANI, F. Estratégia em mídias sociais: como romper o paradoxo das redes sociais e tornar a concorrência irrelevante. São Paulo: Campus, 2011.

ComSCORE. 2013 Brazil digital future in focus. S.1., 2013. Disponível em: <http://www.comscore.com/ por/Insights/Presentations_and_Whitepapers/2013/2013_Brazil_Digital_Future_in_Focus>. Acessado em: 8 mai. 2013.

. Top 10 need-to-knows about social networking and where it is headed. S.1. 2012. Disponível em: $<$ http://www.brandchannel.com/images/papers/534_comscore_wp_social_media_report_1212. pdf>. Acessado em: 26 set. 2012.

$$
\frac{\text { Comunicação \& Inovação, PPGCOM/USCS }}{\text { v. 15, n. } 29 \text { (61-80) jul-dez } 2014} 79
$$


Coutinho, M. "Marketing e comunidades: do discurso ao diálogo". Revista da ESPM. São Paulo, v. 14, n. 2, p. 28-39, mar/abr 2007.

Duarte, F; Quandt, C; Souza, Q. O tempo das redes. São Paulo: Perspectiva, 2008.

IDGNOw. Facebook alcança melhor marca no Brasil com 76 milhões de usuários. Disponível em:http:// idgnow.uol.com.br/internet/2013/08/14/facebook-alcanca-melhor-marca-no-brasil-e-ja-chega-a-77-dos-internautas/. Acessado em: 12 jan. 2014.

Ims Health. Overview. Danbury, CT: 2013 Disponível em: <http:/www.imshealth.com/portal/site/ims/ menuitem.ec35b98806417dab41d84b903208c22a/?vgnextoid=913bc9e28f44f210VgnVCM10000071812ca2RCRD\&vgnextfmt=default $>$. Acessado em: 16 mai. 2013.

INFo EXAME. Twitter: o que você ganha com ele? Disponível em: http://info.abril.com.br/noticias/internet/ twitter-o-que-voce-ganha-com-ele-28102009-9.shl. Acessado em: 13 jan. 2014.

Johnson \& Johnson Indústria e Comércio de Produtos para Saúde Ltda. Campanha Ultra-light, In.:Facebook, São Paulo, 2011. Disponível em: <https://www.facebook.com/neutrogenabrasil>. Acessado em: 9 abr. 2013.

. Resultado da campanha "Ultra-light". São Paulo, 2011.

Levine, R. et. al. O manisfesto da economia digital: O Fim dos Negócios Como Nós Conhecemos. Rio de Janeiro: Campus, 2000.

LimeIRA, T.M.V. e-Marketing. 2.ed. São Paulo: Saraiva. 2007.

Marteleto, R. Análise de redes sociais: aplicação nos estudos de transferência da informação. Ciência da Informação. Brasília, v. 30, n. 1, p. 71-81, jan./abr. 2001. Disponível em: <http://revista.ibict.br/ ciinf/index.php/ciinf/article/viewArticle/226>. Acessado em 25 ago. 2012.

Recuero, R. C. Redes sociais na internet: considerações iniciais. In.: Serra, P. Biblioteca on-line de ciências da comunicação. S.1: Bocc, 2004. p. 07 Disponível em <http://www.bocc.ubi.pt/pag/recuero-raquel-redes-sociais-na-internet.pdf $>$. Acessado em 25 Fev. 2013.

. Redes Sociais na Internet. Porto Alegre: Ed. Sulina, 2009.

Serasa Experian. Facebook, YouTube e Orkut são as redes sociais mais visitadas em maio no Brasil, segundo Hitwise. Disponível em: http://www.serasaexperian.com.br/release/noticias/2013/noticia_01247.htm. Acessado em: 12 jan. 2014.

Telles, A. Geração Digital: como planejar o seu marketing para uma geração que pesquisa no Google, se relaciona no Orkut, manda mensagens pelo celular, opina em Blogs, se comunica pelo MSN e assiste vídeos no YouTube. São Paulo: Landscape, 2009.

Terra. País: Facebook segue na liderança em número de visitas. Disponível em:http://tecnologia.terra. com.br/internet/pais-facebook-segue-na-lideranca-em-numero-de-visitas,2bed3119affb0410VgnVCM5000009ccceb0aRCRD.html. Acessado em: 12 jan. 2014.

YIN, R. Estudo de caso: planejamento e métodos. 3.ed. São Paulo. Bookman, 2001.

$80 \frac{\text { Comunicação \& Inovação, PPGCOM/USCS }}{\text { v. 15, n. } 29 \text { (61-80) jul-dez } 2014}$ 